\title{
Aspects of quality control of wind profiler measurements in complex topography
}

\author{
M. Maruri ${ }^{1,2,3}$, J. A. Romo ${ }^{4}$, and L. Gomez ${ }^{3,4}$ \\ ${ }^{1}$ Basque Meteorology Agency (EUSKALMET), Alava, Spain \\ ${ }^{2}$ TECNALIA, Meteo Unit, Alava, Spain \\ ${ }^{3}$ Department of Matemática Aplicada, University of the Basque Country (UPV/EHU), Bilbao, Spain \\ ${ }^{4}$ Department of Ingeniería de Comunicaciones, University of the Basque Country (UPV/EHU), Bilbao, Spain
}

Correspondence to: M. Maruri (mapmamam@ehu.es)

Received: 15 March 2013 - Published in Atmos. Meas. Tech. Discuss.: 13 June 2013

Revised: 24 November 2013 - Accepted: 27 November 2013 - Published: 14 January 2014

\begin{abstract}
It is well known in the scientific community that some remote sensing instruments assume that sample volumes present homogeneous conditions within a defined meteorological profile. At complex topographic sites and under extreme meteorological conditions, this assumption may be fallible depending on the site, and it is more likely to fail in the lower layers of the atmosphere. This piece of work tests the homogeneity of the wind field over a boundary layer wind profiler radar located in complex terrain on the coast under different meteorological conditions. The results reveal the qualitative importance of being aware of deviations in this homogeneity assumption and evaluate its effect on the final product. Patterns of behavior in data have been identified in order to simplify the analysis of the complex signal registered.

The quality information obtained from the homogeneity study under different meteorological conditions provides useful indicators for the best alternatives the system can offer to build wind profiles. Finally, the results are also to be considered in order to integrate them in a quality algorithm implemented at the product level.
\end{abstract}

\section{Introduction}

The Punta Galea wind profiler uses a Doppler beam swinging (DBS) technique, in a configuration of 5 beams: north, south, east, west and vertical (Strauch et al., 1984; Wuertz et al., 1988; Ecklund et al., 1988).
Improvements in operation are constantly implemented so as to be able to identify non-meteorological targets which have degraded the data. The accuracy of the wind profile depends on the fulfillment of the homogeneity assumption in the DBS technique across the region defined by beam directions (Cheong et al., 2008).

Several quality studies have been proposed at the university with the aim of complementing the quality control algorithm of Weber and Wuertz (1991) or Weber et al. (1993) by testing the consistency between modes in common levels and testing the homogeneity for the wind field over the radar.

The quality control algorithm of Weber and Wuertz (1991) works at the consensus level. The consensus files and the consensus database have a column labelled "MET_QC", in which quality information may be included using a flag code. This column uses values between 0 and 9 ( 0 means that data pass all the quality control procedures, 9 means that the consensus algorithm failed, 8 is invalid data and 7 is suspicious data). Other values can be used as qualitative quality metadata information by the service operator. The detection of discrepancies in the homogeneity assumption can be flagged using a value between 1 and 6 .

The main objective of this work is to study whether the homogeneity hypothesis is fulfilled in a complex site such as the Punta Galea wind profiler. Secondary objectives are the detection and labelling of inhomogeneous situations in the wind field in operation and the interpretation of these inhomogeneities according to a meteorological situation and site interactions. 
To that end, the study compared the vertical components of wind (direct from the vertical beam $W_{\mathrm{v}}$ and derived from the oblique beams, $W_{\text {ns }}$ and $W_{\text {ew }}$ ). The study also classified situations by behavioural patterns in several meteorological situations. Deviations of the initial systematic hypothesis were identified within the first kilometre in relation to determined meteorological situations. The detection and evaluation of these deviations, in association with each datum were considered along with other quality metadata information, which could then be added to the database. The results obtained show how important the homogeneity of surroundings is in order to fulfill the hypothesis of homogeneity in the lower layers.

Therefore, the wind field's homogeneity should be tested in boundary layer wind profiler radars with similar technical characteristics and a similar geographical situation. We also believe that the methodology used could be indirectly generalized to other remote DBS systems.

\section{System description}

The LAP-3000 wind profiler radar was installed in 1996. It is located in Punta Galea, a cape on the coast of Biscay, close to an urban area with the highest population density in Basque Country: Bilbao. It is a boundary layer wind profiler with radio acoustic sounding system (RASS) option; a description of the system was made by Alonso et al. (1998). Figure 1 shows the complex site of the Punta Galea wind profiler.

The operating frequency is $1290 \mathrm{MHz}$. It works in two alternate modes, taking into account height coverage with the best resolution. Low mode (high-resolution) uses the shorter pulse $(60 \mathrm{~m})$ and reaches $2 \mathrm{~km}$. High mode has a lower resolution $(200 \mathrm{~m})$ and reaches higher altitude, up to $8 \mathrm{~km}$ under favourable conditions.

Measurements of wind profiles and temperature profiles are obtained every $30 \mathrm{~min}$. To obtain information on the wind, the radar transmits microwave pulses to the sky in five directions by means of a multidirectional transmitting antenna. One of the microwave beams is vertically directed at the zenith (a direct measurement of the vertical wind, $W_{\mathrm{v}}$ ). The other four beams point in the four cardinal directions. This information is combined to calculate horizontal wind. The dataflow for wind profiling Doppler radars and the improvements in signal processing developed over the years have been described by many authors (Strauch et al., 1984; Ecklund et al., 1988; May and Strauch, 1989; Wilfong et al., 1999; Morse et al., 2002). The stored data include all types along the dataflow, from the time series to the final product (consensus data).

The Punta Galea wind profiler was incorporated in the European Network in September 2006. Since then, the data are quality monitored by the owner of "the Basque Meteorological Service" (www.euskalmet.euskadi.net) and by
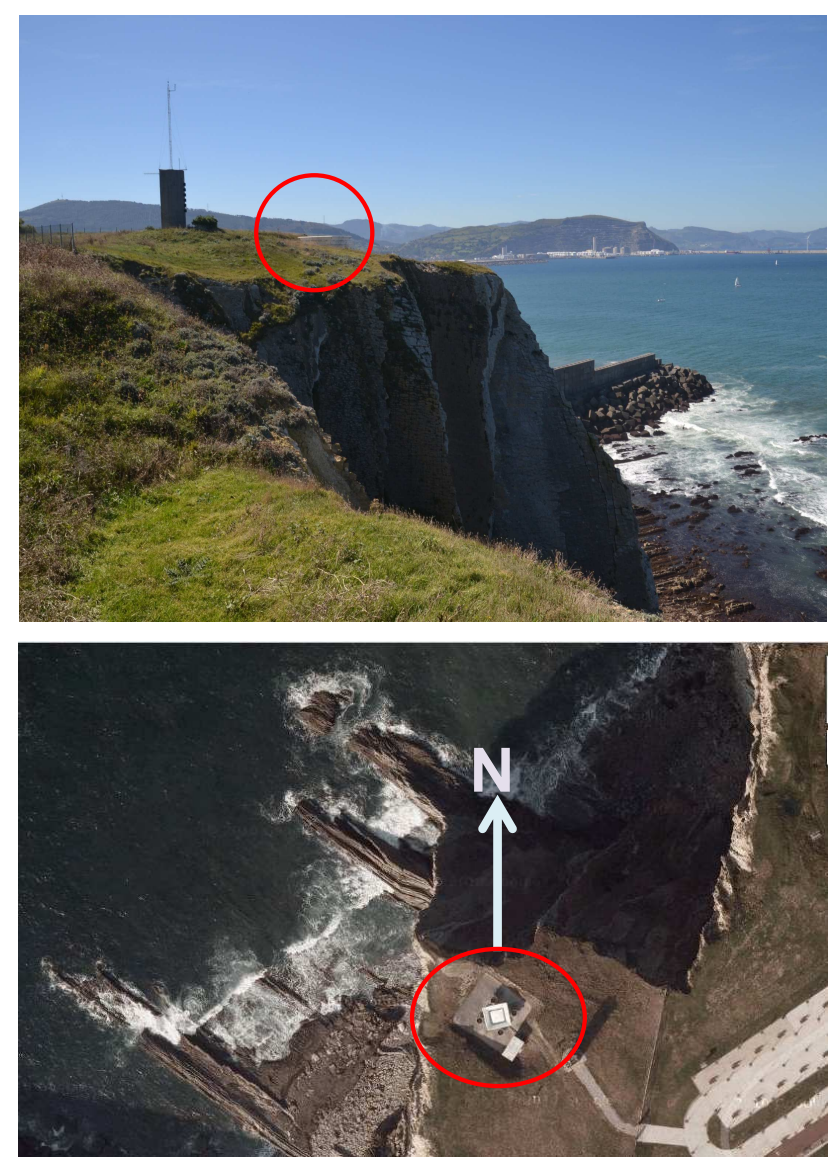

Fig. 1. Geographical location of the Punta Galea wind profiler. Red ellipse indicates the exact location of the site. In top panel, the topography of surrounding area is visualized. Bottom panel, the ground plan of the site is represented and the coastline orientation to the North can be observed.

the Eumetnet wind profile program, Winprof/E-Profile (http: //www.eumetnet.eu/e-profile).

The Basque Meteorological Agency (Euskalmet) has also established a procedure for preventive maintenance in order to monitor the antenna and phase shifter conditions at preestablished intervals. These check-ups assure the quality of the historical database at an instrumental level, making the interpretation of data for scientific purposes easier, among other benefits.

Considering the bulletins and Euskalmet's observations, the days selected for the study were classified by the direction and intensity of the wind according to the automatic weather station, and the complexity of the return signal from meteorological targets, such as clear air echo, precipitation cases (Ralph et al., 1996; Wuertz et al., 1988), non-meteorological targets such as the ground, sea clutter and birds (Wilckzak et al., 1995; Kretzschmar et al., 2003), or a mixture thereof. In addition, other free sources of meteorological information from the Internet were used when such analysis was required. 


\section{Methodology}

The scheme carried out to study the homogeneity of the 5 beams " $W_{\mathrm{v}}=W_{\mathrm{ns}}=W_{\mathrm{ew}}$ " $\left(W_{\mathrm{v}}\right.$ vertical beam, $W_{\mathrm{ns}}$ vertical beam derived from the north and south, $W_{\text {ew }}$ vertical beam derived from the east and west) is described in 4 modules, as can be observed in Fig. 2.

\subsection{Module 1: database selection}

Module 1 (database selection) is the core of the statistical method applied. The main objectives pursued with the development of a robust module 1 are

- simplicity and easy implementation of the homogeneity test in the operation of the wind profiler;

- to search persistent behaviours that could be correlated with patterns detected while monitoring data inspection;

- high reliability and accuracy of the results obtained.

Taking these premises into account, the following aspects of the study were considered in module 1 .

1. The level of data processing.

2. The best statistical tools to examine the data.

3. The evaluation of whether a cleaning module is required or not.

4. The testing period.

\subsubsection{The level of data processing}

In order to identify behaviour patterns, more than one meteorological year of study was needed. Therefore, databases from three meteorological years were used in this study (from 2009 to 2011).

In operational mode, wind profiler systems register information on different levels of data processing: time, spectral and consensus series data.

Time series data provide the most detailed information from the wind profiler. However, the analysis of a very large amount of data is extremely complex and unworkable in practice.

Spectral series data register very useful information for the statistical study of homogeneities but spectral analysis is more complex and it causes operational problems in the implementation of results.

The consensus data are a user product, which provides information about wind velocity in the five directions during the consensus interval time. The consensus information was chosen because of its higher manageability. In an operational sense, the main advantage of this decision would be the fact that the results could be implemented at the consensus level

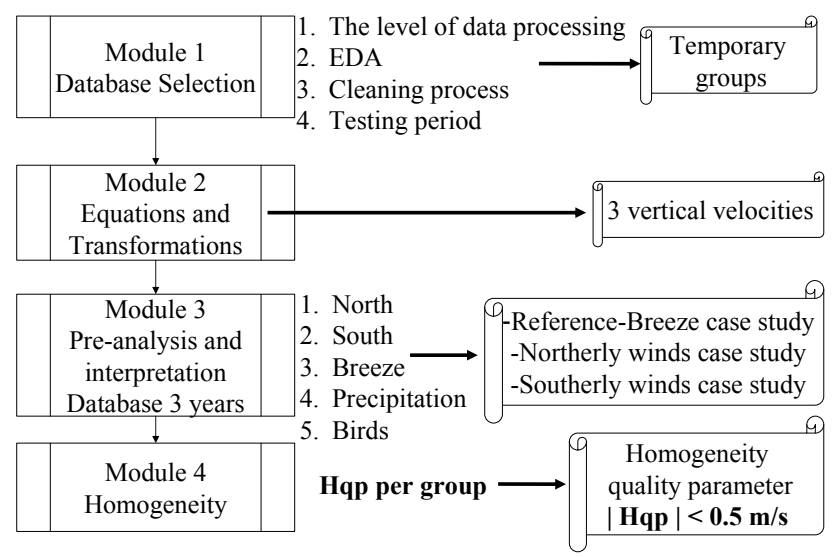

Fig. 2. Schematic overview of the methodology used in the study.

as a complement to the Weber and Wuertz (1991) or Lambert et al. (2003) algorithms.

Complementary meteorological information was considered, together with a previous analysis of consensus data, mainly in the lower layers of the atmosphere.

\subsubsection{The statistical tools}

The exploratory data analysis (EDA) is the statistical method used in this study (Tukey, 1977). It is a first look at the data. These are tools for observing structures, or the lack thereof, in the data. EDA techniques include visual exploration of the data (plots of the time series, stem and leaf displays, boxplots, bar tables, scatterplots) and descriptive statistical analysis of the sample and subsamples.

It is a critical module, since the statistical model of the method is influenced by quality aspects. These quality aspects are detailed with daily and monthly monitoring reports as well as reports of severe meteorology case studies. The interpretation of the quality of observations with the statistical results is crucial for making good decisions.

\subsubsection{The cleaning module}

The cleaning module is a statistical concept used to remove noisy data that are not representative of the study.

\subsubsection{Testing period}

In the testing period of module 1 , the authors worked with a subsample to decide and choose between the different statistical tools of the EDA module of IBM-SPSS software. The tools selected had to offer good representations of the data, control the transformation of data and the behaviour of the three vertical velocities along time and height. Simple plots that take descriptive statistics of population associated with each vertical velocity into account are selected for the study.

The subsample was selected considering severe meteorological episodes, including situations of south wind, north 
wind and precipitation. The previous analysis defined a robust work strategy for the mass treatment of multiple days. During this analysis, the information was explored to assess whether a homogeneous behaviour existed or not $\left(W_{\mathrm{v}}=W_{\mathrm{ns}}=W_{\mathrm{ew}}\right)$.

EDA statistical tools were calculated to decide which was most useful for classification purposes. The design was defined by selecting statistical parameters, which emphasized differences between measurements from all beams. The boxplot tool was a favourite because it comprised all the descriptive parameters in a simple plot.

At this stage the cleaning process is executed. The consensus number showed its capacity to filter random signals that can mask standard situations. In spite of the fact that spectral signal analysis through a sequence would have been more thorough for this study, only information with a $100 \%$ consensus for the 5 beams was considered to ensure that we only included persistent behaviours, and to reduce low SNR (signal to noise ratio) situations. Low SNR could lead to inconsistency cases where the interpretation would have a random component, which is not the main goal of this study.

A temporary classification in groups of similar statistical features under similar meteorological conditions was obtained after visual and statistical exploration of the subsample. Additional information such as spectral data was required so as to verify some suspicious patterns associated with each group. Finally, at the end of this module, preliminary groups and indicators were defined using meteorological criteria, types of targets, and recurrent patterns.

The numerous groups obtained led to the organization of cases in order of priority. The groups of days with poor availability of data in the lower layers were analysed first, followed by cases of strong winds. Precipitation cases and bird migration cases were analysed last, due to the fact that the signals were contaminated by targets other than clear air.

\subsection{Module 2: equations and transformations}

This module is independent of the others, its goal is to define the equations and transformations required for EDA. The equations for the calculation of the vertical components, $W_{\mathrm{v}}$, $W_{\text {ns }}$, and $W_{\text {ew }}$, were calculated for the whole database:

$$
\begin{aligned}
& V_{\mathrm{RN}}=v \cdot \cos \theta+w \cdot \operatorname{sen} \theta+\delta V_{\mathrm{RN}} \\
& V_{\mathrm{RS}}=-v \cdot \cos \theta+w \cdot \operatorname{sen} \theta+\delta V_{\mathrm{RS}} \quad w=W_{\mathrm{NS}}, \\
& V_{\mathrm{RE}}=u \cdot \cos \theta+w \cdot \operatorname{sen} \theta+\delta V_{\mathrm{RE}} \\
& V_{\mathrm{RW}}=-u \cdot \cos \theta+w \cdot \operatorname{sen} \theta+\delta V_{\mathrm{RW}} \quad w=W_{\mathrm{EW}}, \\
& V_{\mathrm{RV}}=w+\delta V_{\mathrm{RV}} \quad w=W_{\mathrm{V}}, \\
& W_{\mathrm{NS}}=W_{\mathrm{EW}}=W_{\mathrm{V}} .
\end{aligned}
$$

Where $\theta$ is the off-zenith angle of the beam; $\delta V_{\mathrm{RN}}, \delta V_{\mathrm{RS}}$, $\delta V_{\mathrm{RE}}, \delta V_{\mathrm{RW}}$, and $\delta V_{\mathrm{RV}}$ the error measurements for each beam; $\boldsymbol{V}(u, v, w)$ the wind vector; and $V_{\mathrm{RN}}, V_{\mathrm{RS}}, V_{\mathrm{RE}}, V_{\mathrm{RW}}$, and $V_{\mathrm{RV}}$ the radial components. Directions are as follows:
$\mathrm{N}$ is north, $\mathrm{S}$ south, $\mathrm{E}$ east, $\mathrm{W}$ west, and $\mathrm{V}$ vertical. Equations (1), (2) and (3) together describe the 3 vertical velocities. Equation (3) shows the direct measurements from the vertical beam. Equation (4) is the homogeneity equation.

The differences between these three vertical velocities $\left(W_{\mathrm{v}}-W_{\mathrm{ns}}, W_{\mathrm{v}}-W_{\mathrm{ew}}, W_{\mathrm{ns}}-W_{\mathrm{ew}}\right)$ were calculated. In addition, these three vertical velocities were used to calculate the differences between them: $W_{\mathrm{v}}-W_{\mathrm{ns}}, W_{\mathrm{v}}-W_{\mathrm{ew}}$ and $W_{\mathrm{ns}}-W_{\mathrm{ew}}$. Among these variables, the homogeneity of the wind field was studied to check if the wind profiler fulfilled the item hypothesis $\left(W_{\mathrm{v}}=W_{\mathrm{ns}}=W_{\mathrm{ew}}\right)$.

The entire previous study was done at high and low modes, although the low gates of both modes were studied and questioned more in-depth.

\subsection{Module 3: pre-analysis and interpretation}

In this module, we analysed the sample (three years of data) according to the results obtained during the testing period (subsample) of module 1 and the equations and transformations of module 2 .

The predominance of the low mode produced biases in the results, caused by the influence of the coastal site. There were certain periods when the predominant target was a non-clearair target, such as bird migration or precipitation. Both modes and the full profile were analysed.

The case study groups were analysed in order, using the following quality criteria: low availability of consensus data and poor quality data (suspicious groups of data after visual inspection). The reference group was a breeze group because of the high SNR inherent in humid sea winds. This situation was considered homogeneous because it offered high-quality data most days.

The second group was the north group versus the south group sorted according to the low availability and multiple peaks in the lower layers. Groups of suspicious data were frequently detected on visual inspection.

Other groups were classified according to the origin of the inconsistencies associated with non-clear-echo targets. The precipitation group and the bird group were also included in this category. Finally, in the west group versus the east group, most of the west group days were included in the precipitation group, and the east component did not show great inconsistencies due to the anticyclonic conditions typical in the area of study.

The results presented in this communication are mostly focused in the north and south groups because the origin of inconsistencies was mainly related to the "site impact".

\subsection{Module 4: homogeneity}

After an exploration of the database suitable for analysis, and the use of different statistical tools (module 3), a final statistical tool for analysis was designed. For each group, a predominant behaviour was associated and patterns of homogeneity 


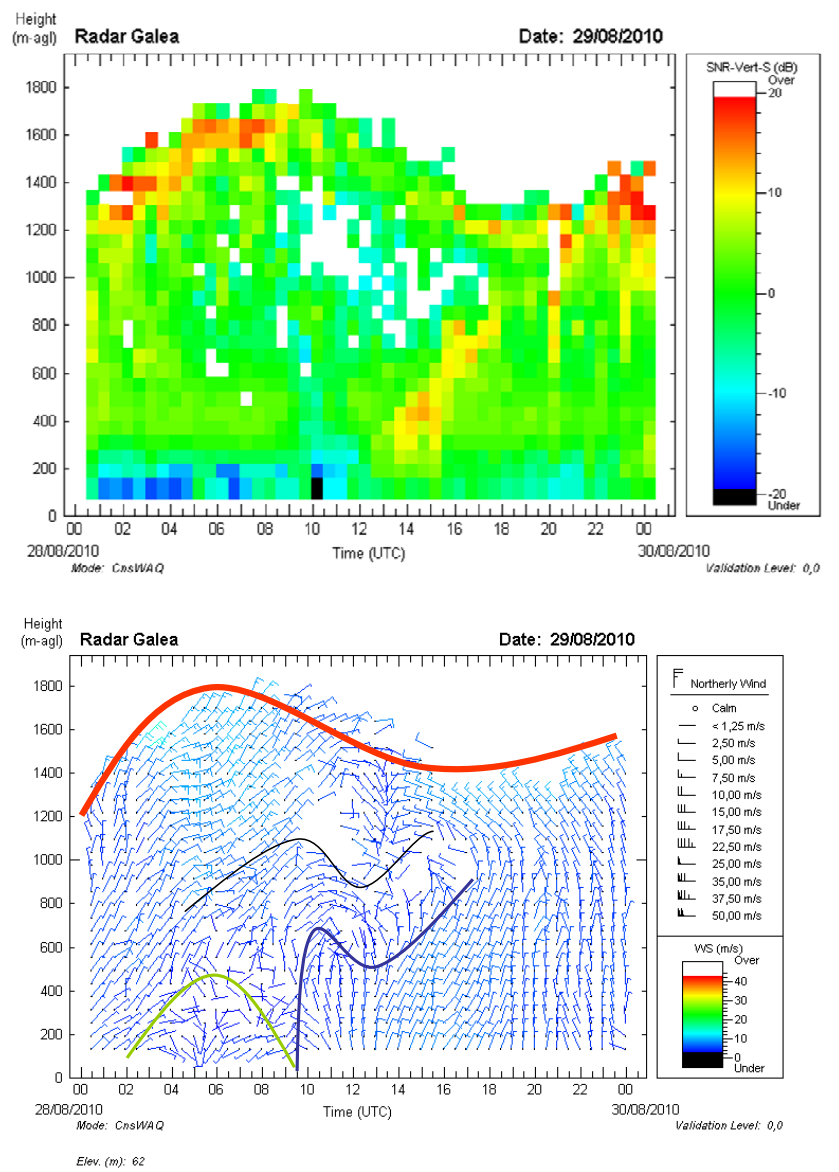

Fig. 3. Breeze pattern: wind profiler observations on $29 \mathrm{Au}-$ gust 2010. (top) Contour, plot SNR. (bottom) Barb plot. $x$ axis (time UTC), $y$ axis (height in m a.g.l. - above ground level). Red line represents the height of the mixing layer. Blue line indicates the height of the land winds. Orange line expresses the height of the sea winds. Black line denotes the limit of the intermediate layer.

deviations were detected. More complex groups also had to be analysed according to their characteristic problems (precipitation and bird groups).

The main goal of this module was to develop an empirical parameter that discriminates between consistent and nonconsistent behaviour along the three vertical components. This empirical parameter was a threshold whose value was calculated using EDA analysis.

To achieve the overall objective of this module, a quality homogeneity parameter "Hqp" had to be defined. In general, a quality parameter gives quality information regarding the data (invalid, suspicious, valid ). The quality homogeneity parameter was a threshold, which flagged data in one of these categories according to the homogeneity test being applied. This type of quality parameter was easy to implement using a numerical code in the same way the quality control module was implemented by the system (MET_QC).
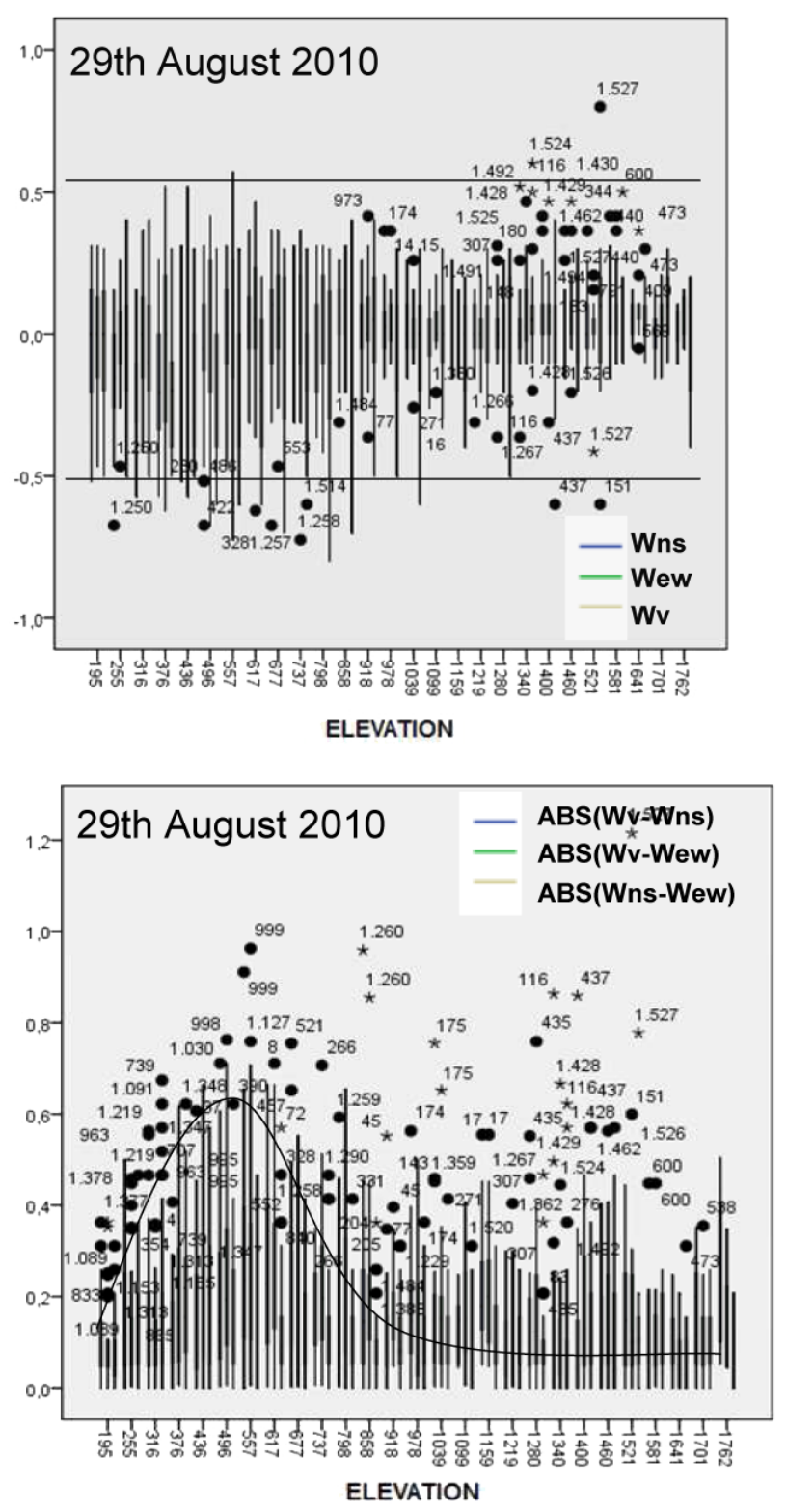

Fig. 4. Breeze pattern: box plots on 29 August 2010. (top) Vertical velocities versus height. (bottom) Absolute values of the differences between velocities versus height. $x$ axis (height in ma.s.l. - above sea level). $y$ axis (velocity in $\mathrm{ms}^{-1}$ ). Black line denotes the envelope curve of the 3 rd quartile.

The quality threshold was calculated statistically, using observable deviations in the homogeneity hypothesis $\left(W_{\mathrm{v}}=\right.$ $\left.W_{\mathrm{ns}}=W_{\mathrm{ew}}\right)$ in an empirical manner. The homogeneity pattern and a potential threshold were then extracted for each study period. The homogeneous case was identified along with the meteorological situations in which the distances between the three measurements were at a minimum and constant along time and height. Therefore, the value found was explained by means of technical specifications and 
operational parameters within the signal processing. The velocity resolution is $0.174 \mathrm{~m} \mathrm{~s}^{-1}$ in the low mode and $0.188 \mathrm{~m} \mathrm{~s}^{-1}$ in the high mode. The ratio between the empirical value "Hqc" and the velocity resolution is calculated. A lower ratio is a good indicator of consistency.

The most homogeneous case was the breeze group in which the threshold could be fixed at $0.5 \mathrm{~m} \mathrm{~s}^{-1}$ with a tolerance of $0.25 \mathrm{~m} \mathrm{~s}^{-1}$ in the low mode. This threshold is set as the maximum value reached by the third quartile curve defined in the series of the absolute distance between the three vertical velocities. It represents the lower ratio of the groups studied.

\section{Results}

The results obtained from the study of the wind profiler historical database from 2009 to 2011 were presented. The results correspond to the study periods described in the methodology.

The study was focused on the low mode, because the homogeneity hypothesis fails more often in this mode. A systematic pattern related to the meteorological conditions was identified. The reason for this behaviour was the interaction with the site during moderate and strong winds. In other cases the item hypothesis failed because of the presence of targets such as birds or hydrometeors, which contaminated the signal and either did not show a homogeneous behaviour in the 5 beams or even did not follow the regime of the wind field, as usually happens with bird groups. If the degree of contamination is different in each beam, and the signal processor presents difficulties for the identification of the peak in clear air, then this situation can cause inhomogeneity in the selected peaks. In these cases, both modes were analysed since the site impact was not the cause of the inhomogeneity.

\subsection{Breeze case}

The breeze case consists of a wind structure developed over the land near the coast with a day-long cycle. During the day, the wind blows from sea to land; that is, the Basque sea breeze component, which comes mainly from the north, with a slight change from west to east during the day. At night, the situation changes; the wind usually blows from land to sea; that is, the Basque land breeze blows from the south, most commonly the southeast.

In both sea and land breezes, the direction is influenced by coastal orientation. These winds occur when a high temperature gradient between land and sea is present, but the shape, the height and the evolution during the day depend on this gradient among other meteorological factors, and its behaviour changes monthly according to the climatology of the area.

The days selected for the study were summer episodes in which the sea breeze occurred almost everyday (from June to
September 2010, and 2011). The main features of the vertical velocity profile from the three vertical velocities $W_{\mathrm{v}}, W_{\mathrm{ns}}$ and $W_{\text {ew }}$, showed values between -0.5 and $0.5 \mathrm{~m} \mathrm{~s}^{-1}$. Thus, the standard deviations were lower than in other cases; although in lower layer of the atmosphere (less than $1 \mathrm{~km}$ ) the values of the standard deviations were higher.

Figures 3 and 4 show a typical breeze pattern registered during those days.

\subsection{North wind case}

In situations of north wind with no rainfall, the vertical velocity from the north-south beams $\left(W_{\mathrm{ns}}\right)$ showed a negative bias while the $W_{\text {ew }}$ showed more variability, which is more consistent with the behaviour of $W_{\mathrm{v}}$, (see Fig. 7). This pattern had a correlation with wind speed and direction. All the study cases had a north component, but there were subtle differences depending on whether this north component came from the west or from the east (i.e. the pattern was not the same with NW or NE winds). The orientation of the coast with respect to the wind direction was considered to be an explanation of this result. The maximum height where inhomogeneity was detected was directly related to the wind speed.

The performance of the wind profiler in northern meteorological situations was satisfactory due to humid air masses from the sea, which generated an adequate SNR in the return signal (Fig. 6). However, we must consider that many of these situations were combined with precipitation and rough sea conditions (large sea waves), both of which are targets that could mask our results. Furthermore, the vertical signal from the north-south $W_{\text {ns }}$ also had a higher dispersion than the rest, as seen in Fig. 9.

This dispersion decreased along with height until the three vertical velocities were consistent. The greatest mismatch was observed at about $376 \mathrm{~m}$, and therefore, the behaviour analysis of time series at this height was made (Figs. 8, 9). Figures 5, 6, 7, 8, and 9 show a typical north pattern registered in these days.

\subsection{South wind case}

During southerly winds, the pattern found was similar to northerly winds. The main difference was that the bias was positive instead of negative (Fig. 11). The pattern was a mirror of the north case with a more complex meteorological situation. The performance of the wind profiler in south meteorological situations was not satisfactory due to the humid air masses from the land. The air masses coming from the mountains (and producing the Föhn effect) caused lee waves and virga precipitations along their trajectories (Fig. 12). This meteorological situation generated a sinusoidal behaviour with alternative low and high SNR. Low SNR was associated with dry conditions, in which clutter signals dominated over atmospheric signals. When precipitation was detected in 


\section{C042 - Punta Galea}

10332010
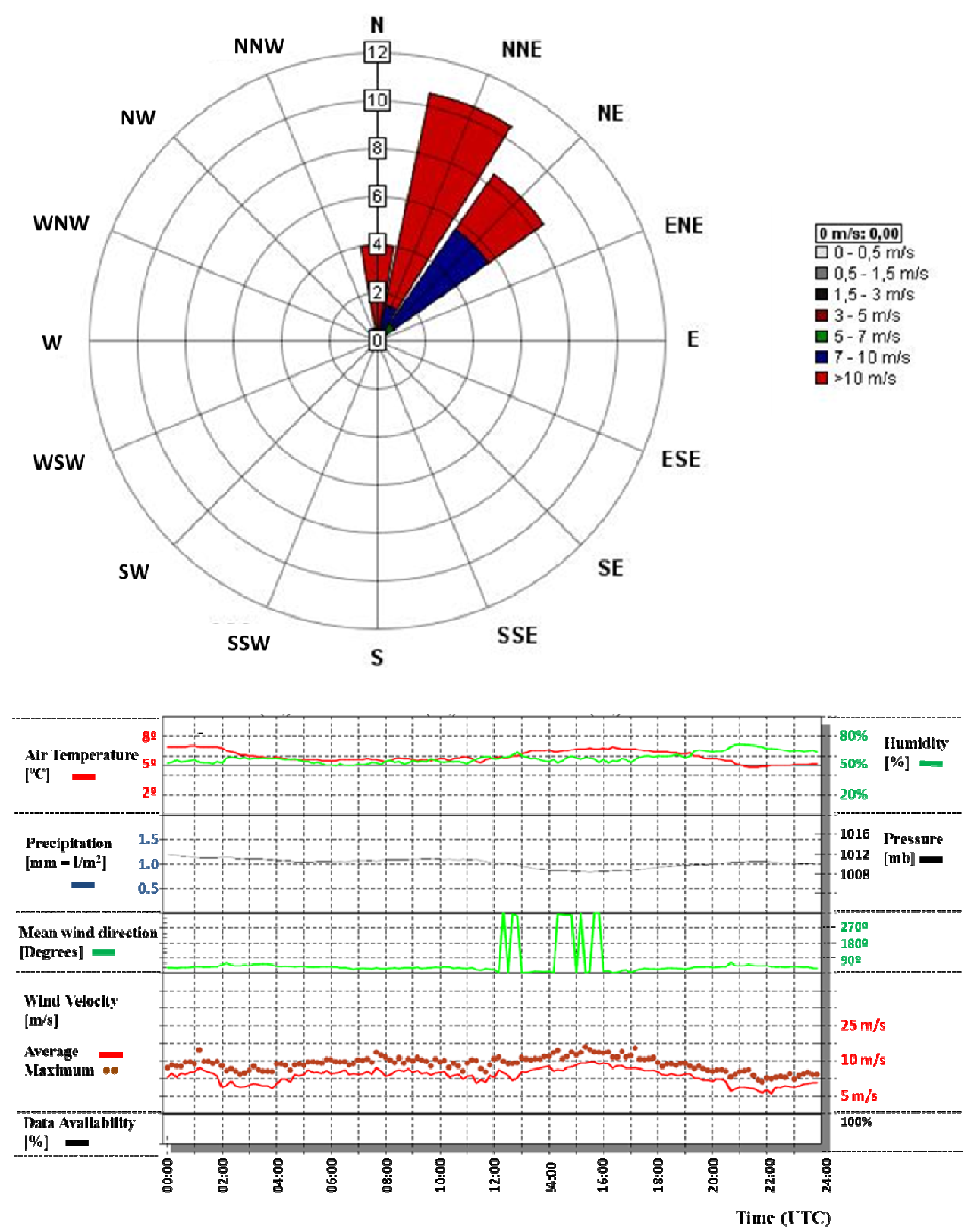

Fig. 5. North pattern: automatic weather station observations on 10 March 2010. (top) Wind rose. (bottom) Meteorological parameter measurements: air temperature, humidity, precipitation, pressure, mean wind direction, and wind velocity.

the higher layers of the atmosphere, these signals could overlap clear air signals and then virga precipitation occurred, which is not as homogeneous as stratiform precipitation. All of these features were presented in the time series of the vertical profile data with sharp changes in the consecutive values. This was the reason for the higher dispersion in the lower layers (Fig. 12). Apart from this, higher contamination of ground clutter in the first gates was commonly detected.
Figures 10,11 , and 12 show a typical south pattern registered in these days.

\subsection{Precipitation case}

The precipitation case produced the most inhomogeneous situations because the nature of precipitation varies greatly in both time and space. For these cases, the methodology 


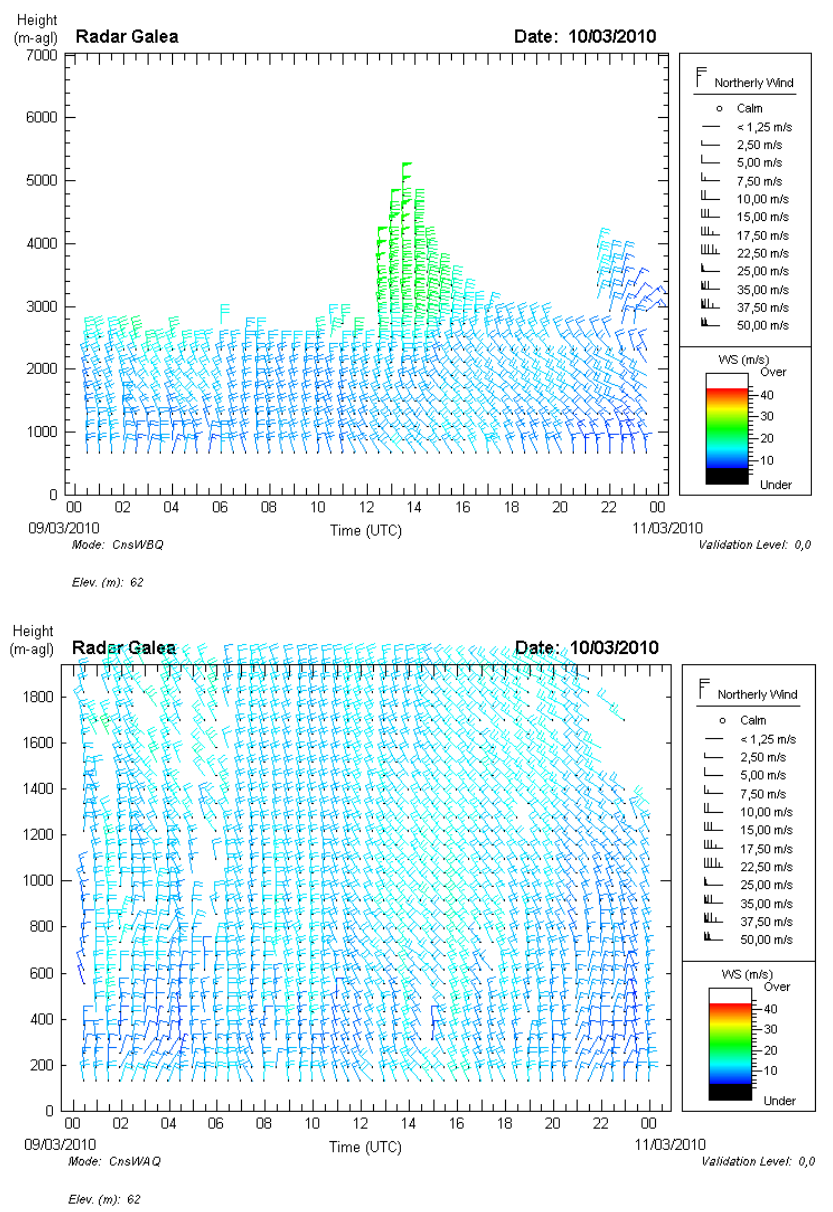

Fig. 6. North pattern: wind profiler observations on 10 March 2010. (top) Barb plot for high mode observation with resolution of $200 \mathrm{~m}$. (bottom) Low mode observation with resolution of $60 \mathrm{~m} . x$ axis (time UTC). $y$ axis (height in ma.g.1.).

presented for the rest of the study was not applied, since $30 \mathrm{~min}$ is a long period of time compared to the time variability of rainfall. Consequently, the methodology for precipitation was modified and it considered a complete 5-beam sequence, which means less than 5 min for each mode. Checking 5-beam precipitation consistency before calculating the consensus was crucial. Thus, more than one statistical pattern was found, and only persistent precipitation situations could be considered homogeneous and provide relevant meteorological information. Some preliminary studies with a temporal 5 min resolution were made at this stage. Figures 13, 14, and 15 show results of the homogeneity study in a stratiform precipitation episode.

\section{Discussion}

The motivation for this work started during monitoring tasks. The visual identification revealed some bias in the lower layer of the atmosphere, which had a correlation with wind
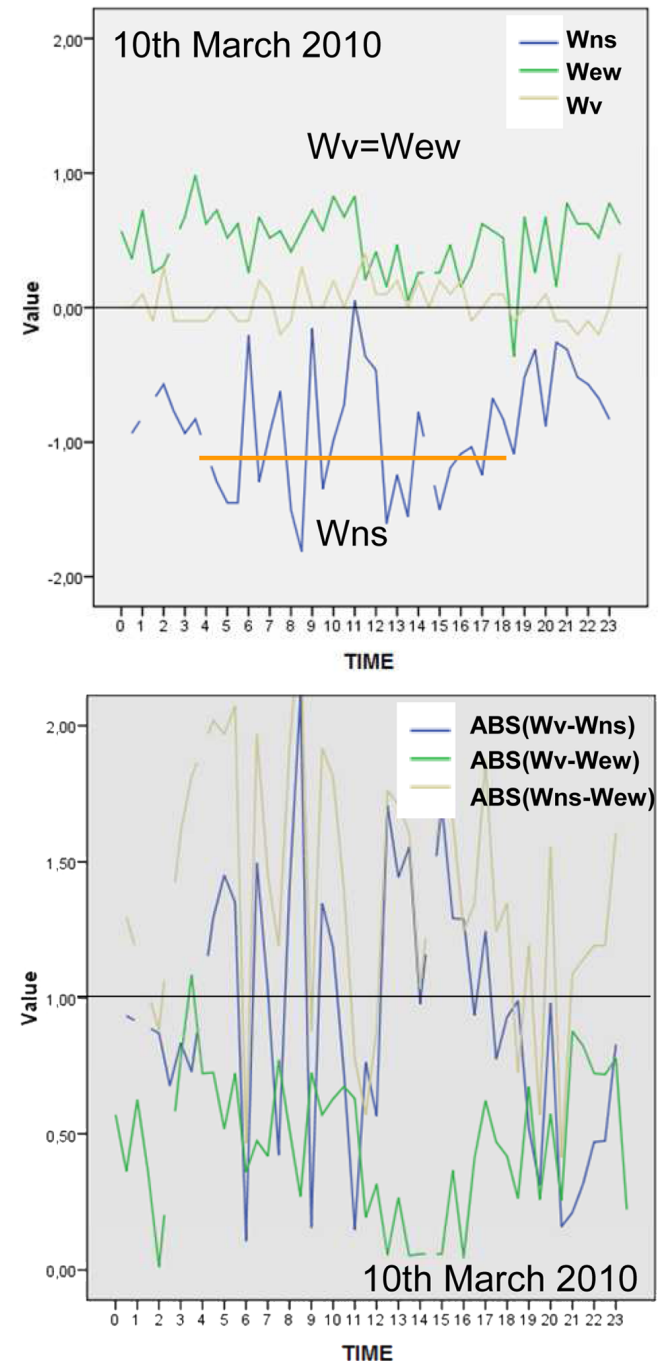

Fig. 7. North pattern: time-series plots on 10 March 2010. (top) Vertical velocities. $x$ axis (time UTC). $y$ axis (velocity in $\mathrm{ms}^{-1}$ ). The orange line indicates the negative deviation of $W_{\mathrm{ns}}$. (bottom) Absolute values of the differences between velocities. $x$ axis (time UTC). $y$ axis (velocity in $\mathrm{m} \mathrm{s}^{-1}$ ).

speed and wind direction. Using this information, it was necessary to confirm this suspicious pattern with a statistical tool and quantify and qualify the situation. Once the deviations had been evaluated numerically, the goal was to design a quality homogeneity parameter "Hqp" capable of detecting deviations in the homogeneity assumption, at least at the consensus level as a first approach. In that sense, a deep discussion of the results and establishing the possible causes of these deviations was required. Since these deviations were related to severe wind episodes, and also, since most wind alerts of the Basque Meteorological Service on these days corresponded to southerly and northerly winds, these two situations were the focus of this work. 


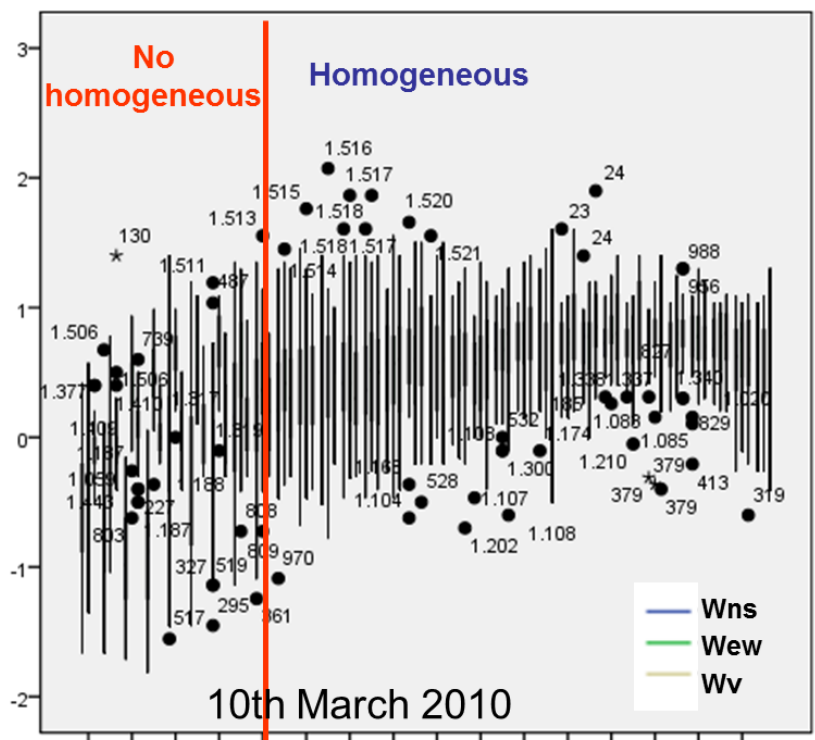

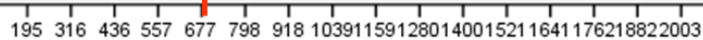
ELEVATION

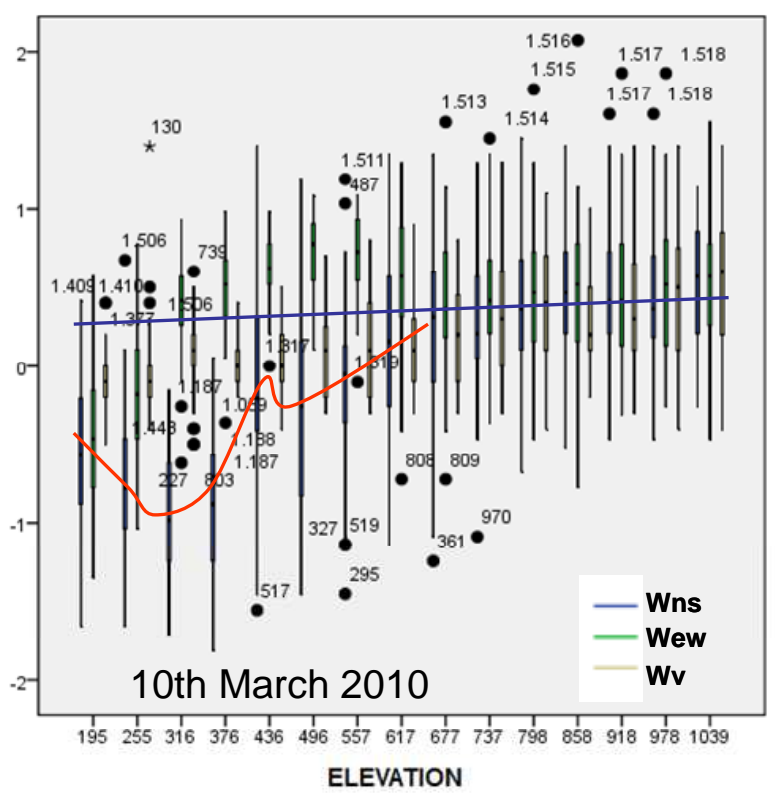

Fig. 8. North pattern: box plots of the vertical velocities on 10 March 2010. $x$ axis (height in ma.s.l.). $y$ axis (velocity in $\mathrm{m} \mathrm{s}^{-1}$ ). (top) Velocities up to the height of $2000 \mathrm{~m}$. Red line represents the limit line between "no homogeneous" and "homogeneous" areas. (bottom) Zoom of the first kilometre. Red line indicates the deviations. Blue line represents the trend.

Tables 2 and 3 reveal a mirrored behaviour dependent upon wind direction with respect to the orientation of the coast. This could be related to the aerodynamic explanation of what happens with the airflow when it passes from a sea surface to a land surface and the role of the cliff in trajectories. In Tables 2 and 3, the first column is the name of the consensus file. Consensus files are daily files that use Julian day format

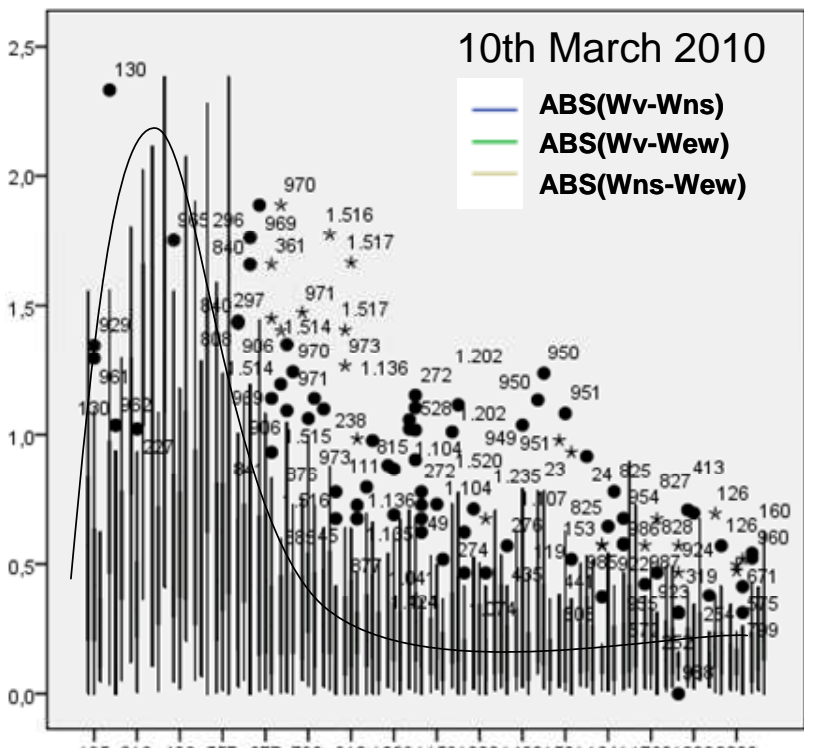

195316436557677798918103911591280140015211641176218822003

FI FVATION

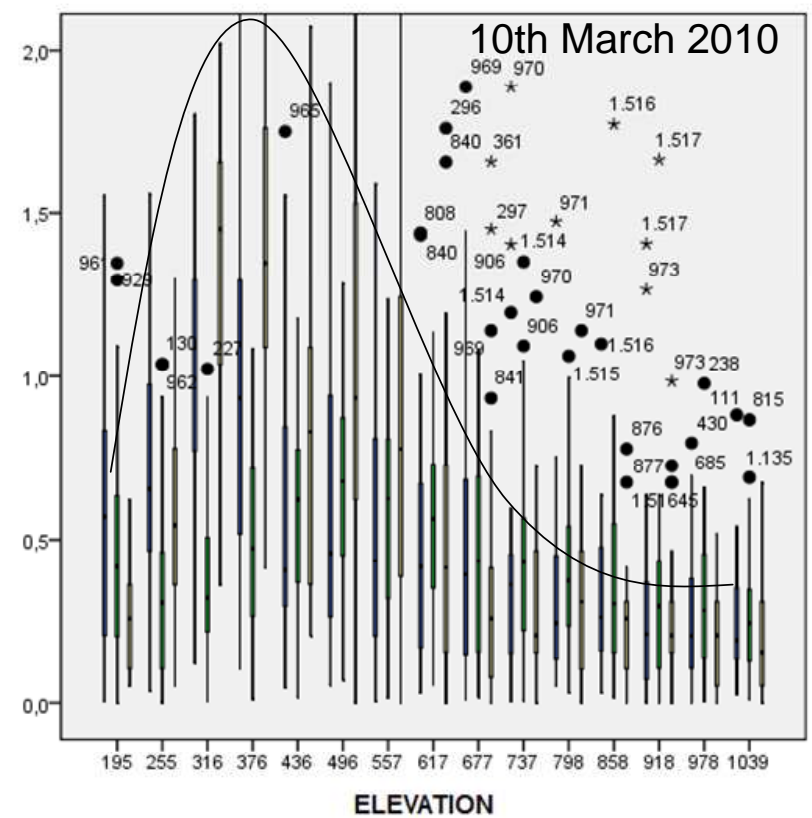

Fig. 9. North pattern: box plots of the absolute values of differences between velocities on 10 March 2010. (top) Differences between velocities up to a height of $2000 \mathrm{~m}$. $x$ axis (height in m a.s.l.). $y$ axis (velocity in $\mathrm{m} \mathrm{s}^{-1}$ ). Black line represents the envelope curve of the 3rd quartile. (bottom) Zoom for the first kilometre. $x$ axis (height in $\mathrm{m}$ a.s.1.). $y$ axis (velocity in $\mathrm{m} \mathrm{s}^{-1}$ ).

to designate the file name. The radial velocities, including vertical velocities, are measured in $\mathrm{m} \mathrm{s}^{-1}$. The vertical velocities are measurements close to zero. These measurements ranged in the following three groups:

- $0=$ measurements around $0 \mathrm{~ms}^{-1}$, with a tolerance of $\pm 0.25 \mathrm{~m} \mathrm{~s}^{-1}$. 

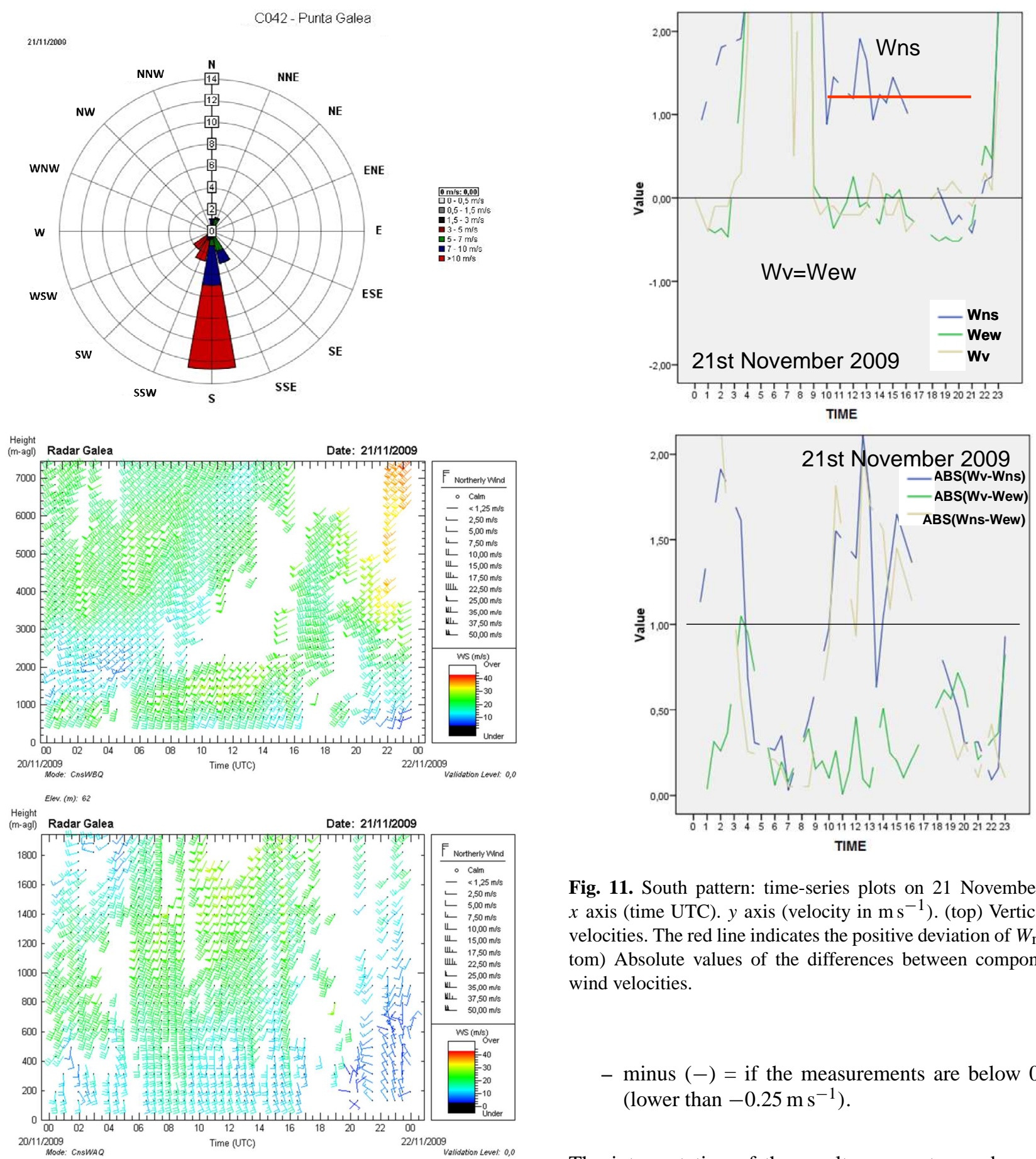

Elev. $(m): 62$

Fig. 10. South pattern: meteorological observations on 21 November 2009. (top) Wind rose derived from the automatic weather station (AWS). (middle) Barb plot for high mode observation with resolution of $200 \mathrm{~m}$. $x$ axis (time UTC). $y$ axis (height in $\mathrm{m}$ a.g.l.). (bottom) Low mode observation with higher resolution of $60 \mathrm{~m}$. $x$ axis (time UTC), $y$ axis (height in ma.g.l.).

- plus $(+)=$ if the measurements are above $0 \mathrm{~m} \mathrm{~s}^{-1}$ (bigger than $0.25 \mathrm{~m} \mathrm{~s}^{-1}$ ).

- minus $(-)=$ if the measurements are below $0 \mathrm{~m} \mathrm{~s}^{-1}$ (lower than $-0.25 \mathrm{~m} \mathrm{~s}^{-1}$ ).

The interpretation of the results was not easy because the SNR was not a stable value along these episodes (northern humid conditions versus southern dry conditions). The statistical values showed a negative/positive bias in the mean and the median regarding the northerly and southerly winds in the vertical velocity derived from the north-south beams (Table 1). These results were confirmed by visual inspection.

The threshold of the quality homogeneity parameter could be fixed using these statistical values as a reference, and it could be active under specific meteorological conditions (north and south winds). The "Hqp" the homogeneity quality 

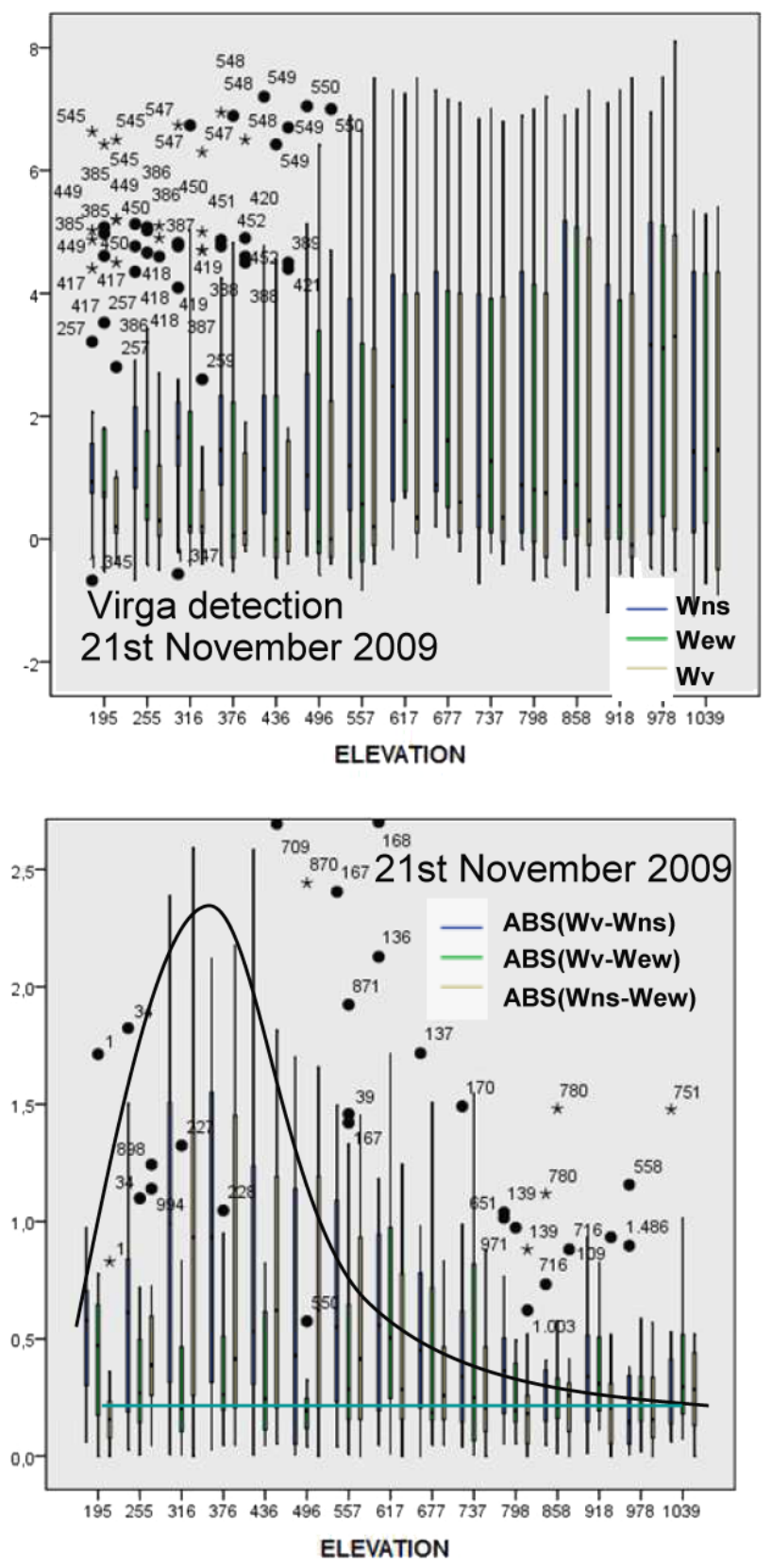

Fig. 12. South pattern: box plots on 21 November 2009. $x$ axis (height in ma.s.l.). $y$ axis (velocity in $\mathrm{ms}^{-1}$ ). (top) Vertical velocities versus height. (bottom) Absolute values of the differences between velocities versus height. Black line represents the envelope curve.

parameter is set to $0.5 \mathrm{~m} \mathrm{~s}^{-1}$ as an empirical quality parameter.

In operational implementation, it would be necessary to add other parameters such as a counter that indicates a constant behaviour in time, as well as a height counter that controls the gates affected below this. Table 1 shows statistical results of the north and south cases.
Table 1. Statistical results from the north and south case studies.

\begin{tabular}{lrrrrrrrr}
\hline & \multicolumn{3}{c}{ North case } & & \multicolumn{3}{c}{ South case } \\
\cline { 2 - 4 } \cline { 7 - 9 } Number of cases & 21616 & 21686 & 27741 & & 17769 & 19048 & 25278 \\
$\left(\mathrm{~m} \mathrm{~s}^{-1}\right)$ & $W_{\mathrm{ns}}$ & $W_{\text {ew }}$ & $W_{\mathrm{v}}$ & & $W_{\mathrm{ns}}$ & $W_{\text {ew }}$ & $W_{\mathrm{v}}$ \\
\hline Mean & 0.27 & 0.43 & 0.48 & & 0.53 & 0.30 & 0.21 \\
Median & 0.00 & 0.21 & 0.20 & & 0.21 & 0.00 & -0.10 \\
25th percentile & -0.31 & -0.10 & -0.10 & & -0.05 & -0.26 & -0.40 \\
50th percentile & 0.00 & 0.21 & 0.20 & & 0.21 & 0.00 & -0.10 \\
75th percentile & 0.62 & 0.78 & 0.70 & & 0.72 & 0.41 & 0.30 \\
\hline
\end{tabular}

Table 2. Trend of the north case study.

\begin{tabular}{lcccl}
\hline $\begin{array}{l}\text { Day } \\
\text { WaaJJ dd-mmm }\end{array}$ & $\begin{array}{c}W_{\mathrm{v}} \\
\left(\mathrm{m} \mathrm{s}^{-1}\right)\end{array}$ & $\begin{array}{c}W_{\mathrm{ns}} \\
\left(\mathrm{m} \mathrm{s}^{-1}\right)\end{array}$ & $\begin{array}{c}W_{\mathrm{ew}} \\
\left(\mathrm{m} \mathrm{s}^{-1}\right)\end{array}$ & Meteorological notes \\
\hline W09307 3 Nov & 0 & - & - & NW \\
W09308 4 Nov & 0 & - & - & Precipitation NW \\
W09349 15 Dec & + & - & + & NNE \\
W09352 18 Dec & + & - & + & NNE \\
W10028 28 Jan & 0 & - & 0 & NW \\
W10029 29 Jan & + & - & + & Precipitation NW \\
W10068 9 Mar & 0 & - & + & NNE \\
W10069 10 Mar & 0 & - & + & NNE \\
W10086 27 Mar & 0 & - & 0 & NNW \\
W10091 1 Apr & 0 & 0 & 0 & NNW \\
W10093 3 Apr & 0 & - & - & NW \\
W10113 23 Apr & 0 & 0 & 0 & NNW \\
W10325 21 Nov & 0 & - & - & Precipitation NNW \\
W10329 25 Nov & 0 & - & 0 & Precipitation NNE \\
W10348 14 Dec & 0 & - & + & NNE \\
W10349 15 Dec & 0 & - & + & NNW \\
W10357 23 Dec & + & - & + & NNW \\
W10358 24 Dec & + & - & + & Precipitation NNE \\
W11030 30 Jan & 0 & - & + & Precipitation NNE \\
W11031 31 Jan & 0 & - & + & NNE \\
W11060 1 Mar & 0 & - & + & NNE \\
W11061 2 Mar & 0 & - & + & NNE \\
W11062 3 Mar & 0 & - & + & NNE \\
W11099 9 Apr & 0 & - & - & NW \\
W11100 10 Apr & 0 & - & + & NW \\
W11101 11 Apr & 0 & - & - & NW \\
W11281 8 Oct & 0 & - & 0 & N \\
Results & 0 & - & $(-, 0,+)$ & \\
\hline & & & & \\
\hline
\end{tabular}

It is well known that radar wind profilers are contaminated by birds during their seasonal migration periods (Wilczak et al., 1995; Richner and Kretzschmar, 2001). Removing the bird signals from the registered signal has long been a challenge (Merrit, 1995; Jordan et al., 1997; Kretzschmar et al., 2003; Lehmann, 2012). In the case of bird migration, the density of the contamination is a crucial parameter, which must be taken into account. Bird migration between February and the beginning of May affected the Basque wind profiler. During this period, birds migrate to the north of Europe to spend the summer. Bird types and the wind conditions are correlated, but in any case, birds interact with the extreme meteorological conditions studied in the south and north cases. Not only must precipitations be studied in more detail, but also bird contamination, as well as the homogeneity assumption. Moreover, the methodology must include specific modules for these types of targets. In the case of bird migration, a bird density parameter and homogeneity must be considered together to find automatic indicators for these targets. 


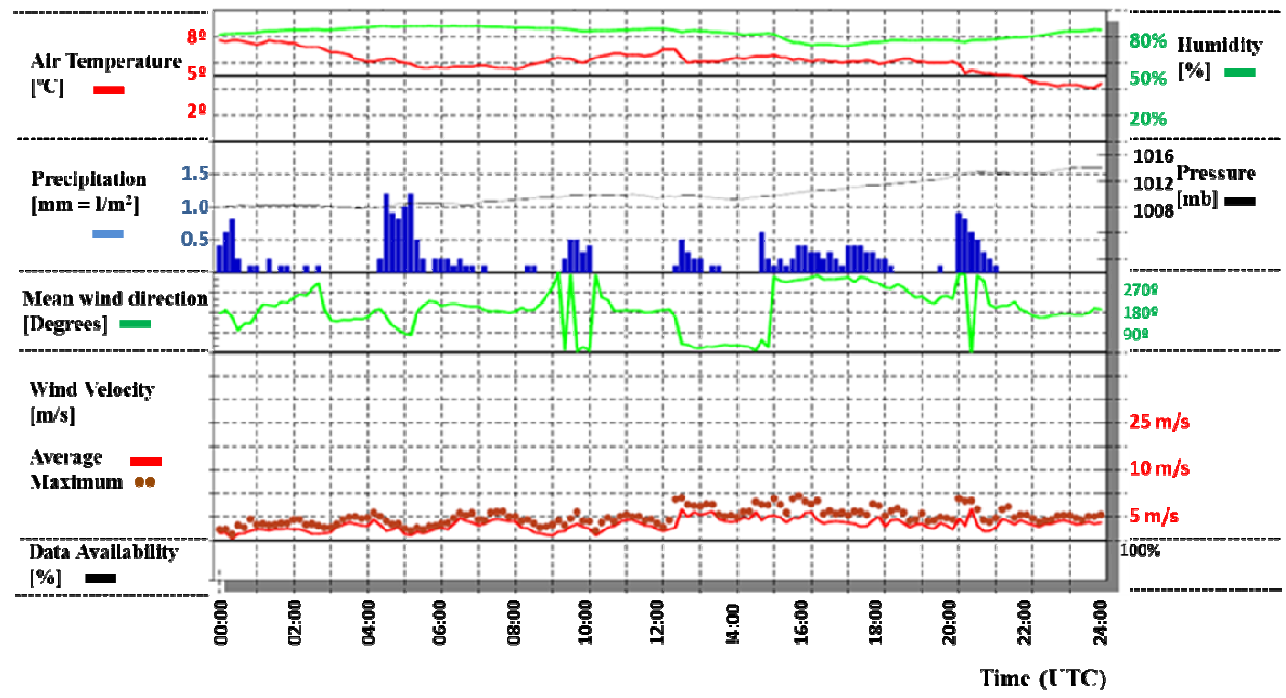

Fig. 13. Stratiform precipitation pattern: meteorological observations plot from the automatic weather station (AWS) on 31 January 2010 , including air temperature, humidity, precipitation, pressure, mean wind direction, and wind velocity.

Table 3. Trend of the south case study.

\begin{tabular}{|c|c|c|c|c|}
\hline $\begin{array}{l}\text { Day } \\
\text { WaaJJJ dd-mmm }\end{array}$ & $\begin{array}{c}W_{\mathrm{v}} \\
\left(\mathrm{m} \mathrm{s}^{-1}\right)\end{array}$ & $\begin{array}{c}W_{\mathrm{ns}} \\
\left(\mathrm{m} \mathrm{s}^{-1}\right)\end{array}$ & $\begin{array}{c}W_{\mathrm{ew}} \\
\left(\mathrm{m} \mathrm{s}^{-1}\right)\end{array}$ & Meteorological notes \\
\hline W09300 27 Oct & 0 & + & 0 & SSE \\
\hline W09301 28 Oct & 0 & + & 0 & SSE \\
\hline W09302 29 Oct & 0 & 0 & 0 & SSE \\
\hline W09323 19 Nov & 0 & + & 0 & $\mathrm{~S}$ \\
\hline W09325 21 Nov & 0 & + & 0 & $\mathrm{~S}$ \\
\hline W09339 5 Dec & + & - & - & $\mathrm{S}$ \\
\hline W09354 20 Dec & 0 & + & - & $\mathrm{S}$ \\
\hline W09355 $21 \mathrm{Dec}$ & 0 & + & - & $\mathrm{S}$ \\
\hline W10276 3 Oct & 0 & + & - & SSW \\
\hline W10278 5 Oct & 0 & + & - & S \\
\hline W10280 7 Oct & 0 & + & 0 & SSE \\
\hline W10281 8 Oct & 0 & + & 0 & SSE \\
\hline W10339 5 Dec & 0 & + & + & S \\
\hline W10341 7 Dec & 0 & + & - & $\mathrm{S}$ \\
\hline W10361 27 Dec & 0 & + & 0 & SSE \\
\hline W10362 $28 \mathrm{Dec}$ & 0 & + & 0 & SSE \\
\hline W10363 29 Dec & 0 & + & 0 & SSE \\
\hline W10364 $30 \mathrm{Dec}$ & 0 & + & 0 & SSE \\
\hline W10365 31 Dec & 0 & + & 0 & SSE \\
\hline W11015 15 Jan & 0 & + & 0 & SSE \\
\hline W11017 17 Jan & 0 & + & 0 & SSE \\
\hline W11274 1 Oct & 0 & + & 0 & SSE \\
\hline W11275 2 Oct & 0 & + & 0 & SSE \\
\hline W11296 23 Oct & 0 & + & 0 & $\mathrm{~S}$ \\
\hline W11299 26 Oct & 0 & + & - & $\mathrm{S}$ \\
\hline W11316 12 Nov & 0 & + & 0 & SSE \\
\hline W11317 13 Nov & 0 & + & 0 & SSE \\
\hline W11318 14 Nov & 0 & + & - & SSE \\
\hline W11322 18 Nov & 0 & + & 0 & SSE \\
\hline W11323 19 Nov & 0 & + & 0 & SSE \\
\hline W11332 28 Nov & 0 & 0 & 0 & SSE \\
\hline W11333 29 Nov & 0 & 0 & 0 & SSE \\
\hline W11334 30 Nov & 0 & + & 0 & SSE \\
\hline Results & 0 & + & (0) & \\
\hline
\end{tabular}

This "Hqp" value could be set as a default value for another boundary layer wind profiler or it could be changed by the operator, taking specific technical features in the system's operation into account. This parameter is set like other algorithm parameters implemented by the system.

\section{Conclusions}

In places where the site does not present homogeneous conditions, the homogeneity of the wind field along the beam directions should not be assumed in the lower layers. The beams could present different interactions (sea clutter, ground clutter, buildings, wind mills, etc.). Therefore, it would be advisable to conduct a study on site impact. Data should be examined under different wind regimes in both low and high modes to test if the homogeneity assumption is valid.

The results would help define the best beam sequence under severe meteorological conditions: whether it is best to use a 3-beam, 4-beam (oblique) or 5-beam sequence (Adachi et al., 2005).

Furthermore, clutter can occur, generally showing a nonhomogeneous behaviour. In these cases, additional measurements on the vertical component can help discriminate the most contaminated beam in order to assess the homogeneity and the behaviour among the beams.

Comparisons of the vertical velocity measured directly by the vertical beam with vertical velocities derived from opposing oblique beams were found to be useful diagnostics in this study. Differences in the vertical velocities were used to indicate inhomogeneous conditions.

The uncertainties in the final product (wind profiles) are not described in this work, since it is currently under evaluation. This is why the work was planned at the spectral level, where more factors than cliff impact are considered. At a consensus level of data, a mathematical exercise of the uncertainties was made in the study group of northerly/southerly winds. In this exercise a deviation in the $W_{\mathrm{ns}}$ of $1 \mathrm{~m} \mathrm{~s}^{-1}$ was used. In northerly/southerly winds, where the radial components of the east and west beams are 


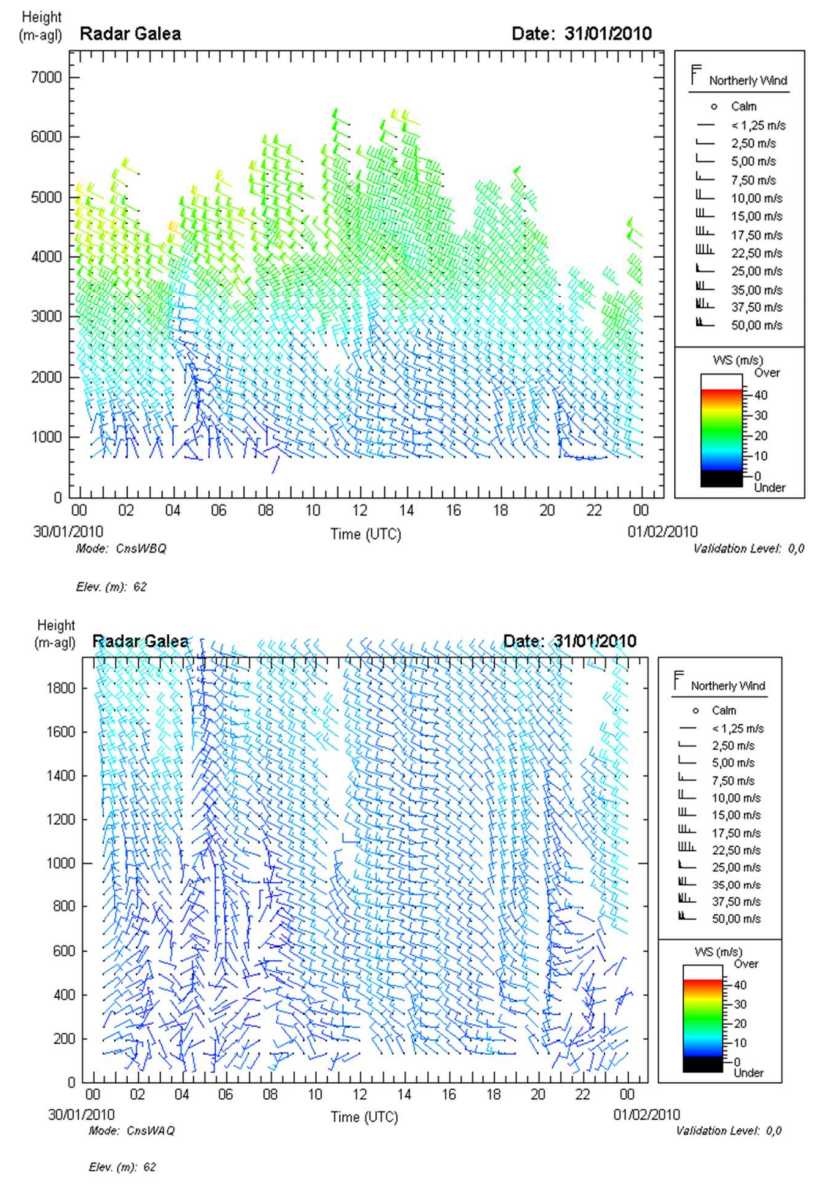

Fig. 14. Stratiform precipitation pattern: meteorological observations plot from the wind profiler (WPR) on 31 January 2010. (top) Barb plot for high mode observation with resolution of $200 \mathrm{~m}$. (bottom) Low mode observation with higher resolution of $60 \mathrm{~m} . x$ axis (time UTC). $y$ axis (height in m a.g.1.).

small, the final product would be biased in the velocity speed (approximately $0.5 \mathrm{~m} \mathrm{~s}^{-1}$ ). The consensus data available during visual inspection in this meteorological situation show good quality profiles, and the deviation of the homogeneity hypothesis has been proved.

The results of this study will help to improve the interpretation of data in the daily monitoring routine by the service operator.

Finally, vertical motion information is extremely useful in several meteorological applications. This study helps to explain the vertical velocity properties of measurements in a boundary wind profiler in a coastal environment. The measurements' properties could be compared with measurements obtained by other vertical pointing radars in similar locations.

Supplementary material related to this article is available online at http://www.atmos-meas-tech.net/7/ 135/2014/amt-7-135-2014-supplement.zip.
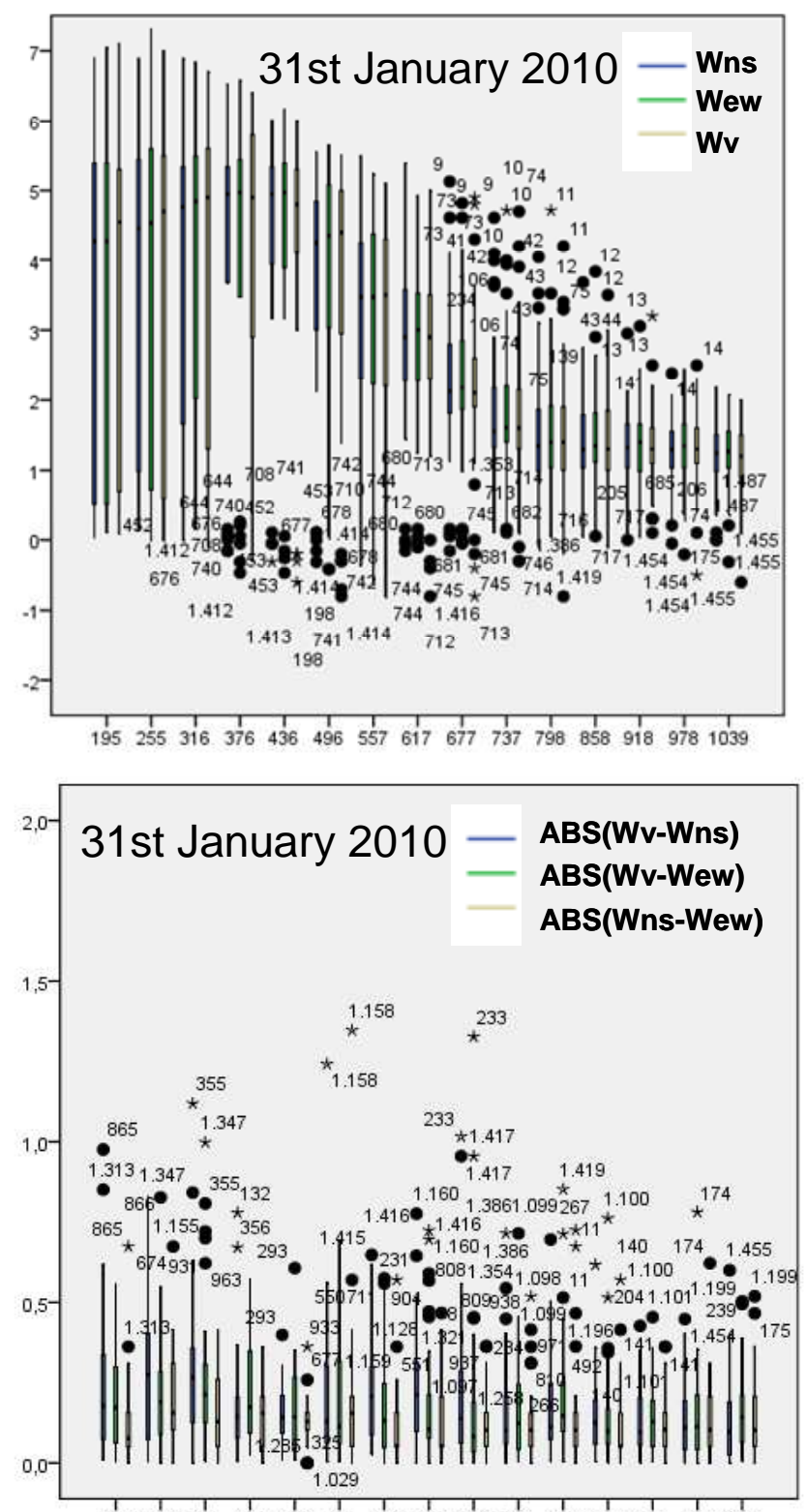

$\begin{array}{lllllllllllllll}195 & 255 & 316 & 176 & 1 & 1 & 1 & 1 & 1 & 1 & 1 & 1 & 1 & 1 & 1\end{array}$

Fig. 15. Stratiform precipitation pattern: box plots on 31 January 2010. $x$ axis (height in $\mathrm{m}$ a.s.1.). $y$ axis (velocity in $\mathrm{ms}^{-1}$ ). (top) Vertical velocities versus height. (bottom) Absolute values of the differences between velocities versus height.

Acknowledgements. The authors thank their colleagues from Euskalmet (Basque Meteorological Agency), for assisting in the evaluation of this paper; the Basque Meteorological Service, for supplying the raw data used in this analysis; and the University of the Basque Country for its support. Finally, we would like to thank Michael Kevin Jones, Ana Bilbao Goyoaga, Louise Cronin and John Bolduan for their English corrections.

Edited by: D. Cimini 


\section{References}

Adachi, A., Kobayashi, T., Gage, K. S., Carter, A., Hartten, L. M., Clark, W. L., and Fukuda, M.: Evaluation of three-beam and four-beam profiler wind measurement techniques using a fivebeam wind profiler and collocated meteorological tower, J. Atmos. Ocean. Tech., 22, 1167-1180, 2005.

Alonso, L., Gangoiti, G., Navazo, M., Maruri, M., Garcia, J. A., and Aranda, J. A.: The Punta Galea boundary layer profiler: Intercomparison with radiosonde data and first mesoscale meteorological case studies, Meteorol. Z., 7, 203-212, 1998.

Cheong, B. L., Yu, T.-Y., Palmer, R. D., Yang, K.-F., Hoffman, M. W., Frasier, S. J., and Lopez- Dekker, F. J.: Effects of wind field inhomogeneities on Doppler beam swinging revealed by imaging radar, J. Atmos. Ocean. Tech., 25, 1414-1422, 2008.

Ecklund, W. L., Carter, D. A., Balsley, B. B.: A UHF Wind profiler for the boundary layer: Brief description and initial results, J. Atmos. Ocean. Tech., 5, 432-441, 1988.

Jordan, J. R., Lataitis, R. J., and Carter, D. A.: Removing Ground and Intermittent Clutter Contamination from Wind Profiler Signals Using Wavelet Transforms, J. Atmos. Ocean. Tech., 14, 1280-1297, 1997.

Kretzschmar, R., Karayiannis, N. B., and Richner, H.: Removal of bir-contaminated wind profiler data based on neural networks, Pattern Recognition (Elseviver), 36, 2699-2712, 2003.

Lambert, W. C., Merceret, F. J., Taylor, G. E., and Ward, J. G.: Performance of five $915-\mathrm{MHz}$ wind profilers and an associated automated quality control algorithm in an operational environment, J. Atmos. Ocean. Tech., 20, 1488-1495, 2003.

Lehmann, V.: Optimal Gabor-Frame-Expansion-Based Intermittent-Clutter-Filtering Method for radar wind profiler, J. Atmos. Ocean. Tech., 29, 141-158, 2012.

May, P. T. and Strauch, R. G.: An examination of wind profiler signal processing algorithms. Notes and Correspondece, J. Atmos. Ocean. Tech., 6, 731-735, 1989.

Merrit, D. A.: A statistical averaging method for wind profiler Doppler spectra, J. Atmos. Ocean. Tech., 12, 985-995, 1995.
Morse, C. S., Goodrich, R. K., and Cornman, L. B.: The NIMA method for improved moment estimation from Doppler spectra, J. Atmos. Ocean. Tech., 19, 274-295, 2002.

Ralph, F. M., Neiman, P. J., and Ruffieux, D.: Precipitation identification from radar wind profiler spectral moment data: vertical velocity histograms, velocity variance, and signal power 15 vertical velocity correlations, J. Atmos. Ocean. Tech., 29, 141-158, 1996.

Richner, H. and Kretzschmar, R.: Bird identification on 1290-MHz wind profiler data applying neural networks and neurofuzzy systems, Phys. Chem. Earth Pt. B, 26, 181-186, 2001.

Strauch, R. G., Merrit, D. A., Moran, K. P., Earnshaw, K. B., and Van de Kamp, D.: The Colorado wind-profiling network, J. Atmos. Ocean. Tech., 1, 37-49, 1984.

Tukey, J. W.: Exploratory Data Analysis, ISBN-10 0201076160 , 1977.

Weber, B. L. and Wuertz, D. B.: Quality control algorithm for profiler measurements of winds and RASS temperatures, NOAA Tech. Memo, ERL WPL-212, 32 pp., 1991.

Weber, B. L., Wuertz, D. B., Welsh, D. C., and McPeek, R.: Quality controls for profiler measurements of winds and RASS temperatures, J. Atmos. Ocean. Tech., 10, 452-464, 1993.

Wilczak, J. M., Strauch, F. M., Ralph, F. M., Weber, B. L., Merritt, D. A., Jordan, J. R., Wolfe, D. E., Wuertz, D. B., Gaynor, J. E., McLaughlin, S. A., Rogers, R. R., Riddle, A. C., and Dye, T. S.: Contamination of wind profiler data by migrating birds: Characteristics of corrupted data and potential solutions, J. Atmos. Ocean. Tech., 12, 449-467, 1995.

Wilfong, T. L., Merrit, D. A., Lataitis, R. J., Weber, B. L., Wuertz, D. B., and Strauch, R. G.: Optimal generation of radar wind profiler spectra, J. Atmos. Ocean. Tech., 16, 723-733, 1999.

Wuertz, D. B., Weber, B. L., Strauch, R. G., Frisch, A. S., Little, C. G., Merritt, D. A., Moran, K. P., and Welsh, D. C.: Effects of precipitation on UHF wind profiler measurements, J. Atmos. Ocean. Tech., 5, 450-465, 1988. 